\title{
$\mathrm{KCS}$ 선형의 천수영역에서의 자세 변화에 대한 실험적 연구
}

윤근항 $^{\dagger} \cdot$ 박병재 $\cdot$ 여동진 ${ }^{1}$

한국해양과학기술원 부설 선박해양플랜트연구소

\section{Experimental Study of Ship Squat for KCS in Shallow Water}

Kunhang Yun ${ }^{1}{ }^{\dagger} \cdot$ Byoungjae Park $\cdot$ Dong-Jin Yeo

Korea Research Institute of Ships \& Ocean Engineering

This is an Open-Access article distributed under the terms of the Creative Commons Attribution Non-Commercial License(http://creativecommons.org/licenses/by-nc/3.0) which permits unrestricted non-commercial use, distribution, and reproduction in any medium, provided the original work is properly cited.

When a ship sails in shallow water, it is well known that an additional sinkage and trim of the ship(squat) is caused by change of hydrodynamic force between the seabed and the bottom of a ship. In this paper, to examine this phenomenon by model tests, the squat of KCS model ship at a low speed is measured by the vision based ship motion measurement system during HPMM tests. Various combinations of a ship speed, a rudder angle and a drift angle were tested at three depth conditions $(\mathrm{H} / \mathrm{T}=1.2,1.5$ \& 2.0). As a result, increase of the ship's speed and ship's drift angle caused an increase in ship squat, but the ship's rudder angle did not. The rate of increase in ship squat was the most at $H / T=1.2$ condition. Lastly these experimental results are compared to the results by three empirical formulas and two CFD methods. The tendency of ship squat measured by experiment is similar to those of empirical formulas.

Keywords : Squat(스쿼트), Sinkage(침하), Shallow water(천수), KCS, HPMM(수평면운동시험)

\section{1. 서 론}

최근 선박의 대형화 추세에 따라 선박의 흘수가 증가하고 있 고, 이에 따라 깊이가 제한되어 있는 항내 천수영역을 운항하는 선박의 수가 상대적으로 증가하고 있다. 천수영역에서 운항되는 선박은, 선박의 선저와 해저면 사이의 유동의 변화에 따라 선체 에 작용하는 동유체력이 변하게 되고 이에 따라 선박의 흘수가 증가하는 이른바 스쿼트 현상이 나타난다. 따라서 연안항로와 같 은 천수영역에서 주로 운항되는 선박은 제한된 수심에 의한 선박 의 흘수 증가 요소를 선박설계에 고려해야 한다 (Kim, et al., 2000).

선박의 스쿼트 현상과 관련된 국외 연구로는 60 년대 이후 많 은 기초 연구가 이루어졌으며, 그 결과로 Tuck모델, Barrass모 델, Eryuzlu모델 등 많은 추정식이 제시되었고 현재 활용되고 있 다 (Beaulieu, 2012; Taylan, 2001). 또한 GPS를 이용한 해상실 험을 통해 실제 스쿼트 현상을 계측하고 이를 추정식과 비교한 많은 연구가 있다 (Beaulieu, 2009; Hewlett, et al., 2002; Tim \& Kim, 2007). 한편 CFD(computational fluid dynamics)관련 연 구로, Jachowski (2008)는 상용 전산유체역학 해석프로그램을 이용하여 KCS(kriso container ship)선형에 대하여 천수조건별
침하현상을 계산하고 이를 추정식 결과와 비교한 연구를 수행하 였다.

국내 연구로는 주로 인하대학교 선형시험수조에서 수행된 실 험과 연구로, 천수영역에서 Series60선형에 대한 저항, 트림, 침 하량을 계측한 실험적 연구와 (Kim, et al., 2000), 고속여객선형 에 대하여 속도별 저항실험을 수행하여 천수영역에 의한 선박의 저항변화에 대하여 연구를 수행한 바 있다 (Kwon \& Lee, 2004). 또한 실험적 방법 외 전산유체역학을 이용한 연구로 Shin \& Choi (2011)는 상용 전산유체역학 해석프로그램을 이용하여 KCS선형 에 대하여 천수조건별 침하현상을 계산하고 이를 추정식 결과와 비교하였다.

본 연구에서는 $\mathrm{KCS}$ 선박의 항만내 운항 상태(속도, 프로펠러 RPS, 타각, 사항각)변화에 따른 스쿼트 현상을 추정하기 위하여, 한국해양과학기술원에 설치된 천수영역시설을 사용하여 KCS선 형의 천수영역에서의 자세변화를 실험을 통하여 관찰하고 분석하 였다. 이를 위해 3 가지 천수조건을 구성하였고, 모형선의 속도, 사항각 등의 변화에 따른 자세변화를 확인하기 위하여, 수평면 구속모형시험의 정적시험 중 모형선의 자세를 모두 계측하였다. 계측된 결과로부터 모형선의 속도, 프로펠러 RPS, 타각, 사항각 에 따른 천수영역에서의 모형선 자세변화를 확인하였고, 천수조 건에 따른 선박의 자세변화는 추정식 및 선행 CFD관련 연구결과 
와 비교하여 그 유효성을 검증하였다. 구속모형시험 중 선박의 자세 계측을 위해서는 영상기반 선박자세 측정시스템을 개발하여 측정에 활용하였다.

\section{2. 영상기반 선박자세 측정시스템}

영상기반 선박자세 측정시스템은 모형선의 6 자유도 운동 (surge, sway, heave, roll, pitch, yaw)을 실시간으로 계측하기 위한 것으로, 모형선 내에 설치된 계측용 판을 고해상도 카메라 를 이용하여 디지털 영상으로 취득하고, 이를 분석하여 모형선의 자세를 추정한다.

측정용 프로그램은 HALCON11.0이라는 상용 라이브러리를 이 용하여 개발되었으며, 카메라 고정좌표계에서 계측용 판의 위치 를 출력하게 된다. 계측용 판에는 미리 알고 있는 형상 정보에 따 르는 49 개의 점이 인쇄되어 있기 때문에, 이들이 이루는 각, 거 리 등을 분석하면 계측용 판의 위치와 자세를 추정할 수 있다. Fig. 1과 같이 자세를 측정하기 위한 모형선의 중심에 계측용 판 을 설치하고, 모형선의 운동과 독립되어 있는 실험장비에 카메라 를 설치하면, 측정용 프로그램을 이용하여 고정된 카메라를 원점 으로 하는 모형선의 자세를 Fig. 2와 같은 과정(초기화, 영상획 득, 영상분석)을 통해 실시간으로 획득할 수 있다.

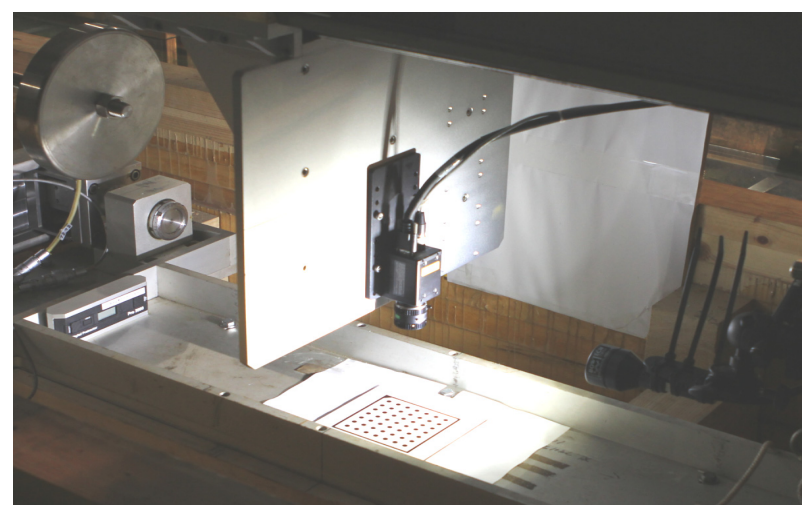

Fig. 1 Ship motion measurement system(SMMS)

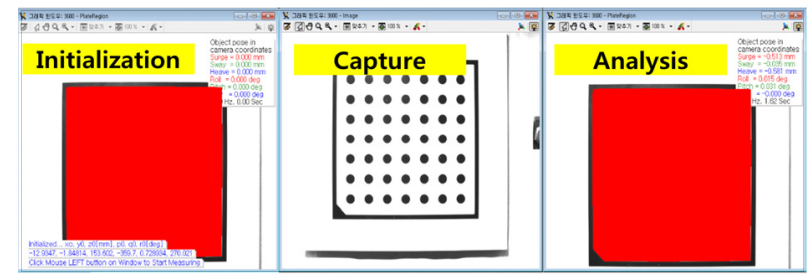

Fig. 2 Process of SMMS measuring

영상기반 선박자세 측정시스템에 사용된 카메라, 계측용 판 등 의 구성요소와 그 제원은 Table 1 과 같다. 실시간으로 정확한 측 정을 하기 위해서 5 백만 화소의 흑백카메라, 서버급 컴퓨터를 사 용하였으며, 결과적으로 모형선의 자세는 평균 초당 6-7회 계측 되었다.
Table 1 Hardware components of SMMS

\begin{tabular}{c|c}
\hline Components & Specification \\
\hline Camera & Sony, XCL-5005 \\
& $5 \mathrm{M}$-pixel, 15 FPS \\
\hline Lens & $\mathrm{ML}-\mathrm{M} 0814 \mathrm{MP}$ \\
\hline Measuring plate & $100 \times 100 \mathrm{~mm}$ \\
& 49 point \\
\hline Capture board & Matrox, SOL 2M EV CLB \\
\hline Computer & CPU : i7 3770k \\
\hline
\end{tabular}

또한 실험 전 영상기반 선박자세 측정시스템의 측정값을 교정 하기 위하여, Fig. 3과 같은 교정용 장비를 이용하여 교정 작업을 수행하였다. 교정 장비는 $0.1 \mathrm{~mm}, 0.1$ 도의 분해능을 가지며, 카 메라 설치방향을 조정하면 6자유도 운동을 구현할 수 있다. 영상 기반 선박자세 측정시스템에서 측정한 측정값과 교정장비에서 설 정한 실제값의 결정계수 $\left(R^{2}\right)$ 는 상하운동, 종동요에 대하여 각각 $0.9999,0.9993$ 으로 선형성을 잘 만족하고 있으며, 실험에서 계 측된 결과는 교정용 값으로 보정된 후 분석에 활용되었다.

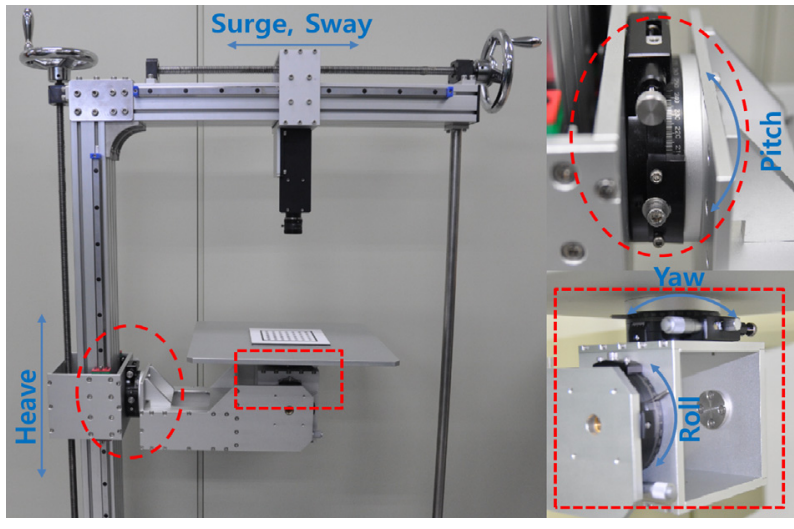

Fig. 3 Calibration device for SMMS

\section{KCS 천수영역 자세측정 실험}

\section{1 천수영역 예인수조 및 대상 선형}

Table 2 Principal dimensions of towing tank, falsebottom

\begin{tabular}{c|c|c|c}
\hline \multicolumn{4}{c}{ Towing tank } \\
\hline Item & Length & Breath & Depth \\
\hline Value & $200 \mathrm{~m}$ & $16 \mathrm{~m}$ & $7 \mathrm{~m}$ \\
\hline \multicolumn{4}{c}{ False-bottom } \\
\hline Item & Length & Breath & Depth \\
\hline Value & $54 \mathrm{~m}$ & $10 \mathrm{~m}$ & $0-7 \mathrm{~m}$ \\
\hline
\end{tabular}


실험이 수행된 한국해양과학기술원의 예인수조와 천수영역을 위한 구조물(false-bottom)의 제원과 모습은 각각 Table 2, Fig. 4와 같다.

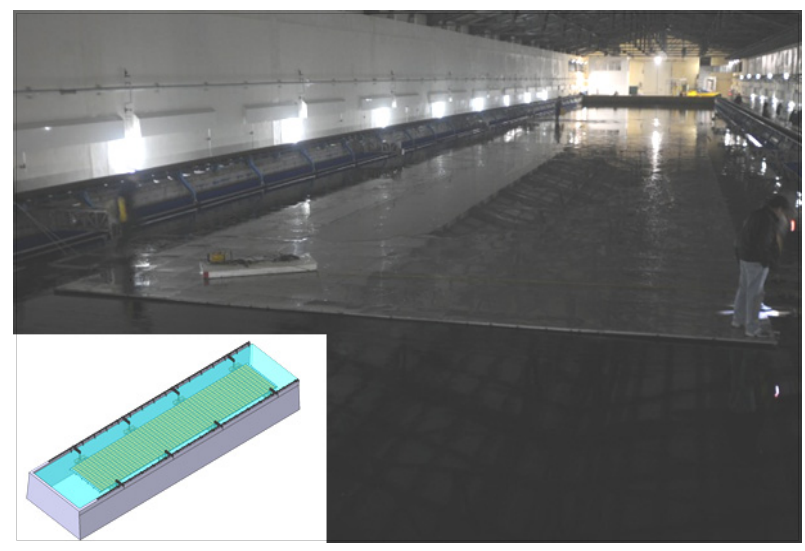

Fig. 4 False-bottom in towing tank

천수조건은 식 (1), Fig. 7과 같이 선박의 흘수와 수심으로 정 의할 수 있고, 주어진 모형선에 대하여 천수용 구조물의 높낮이 를 조절하여 수심을 변경함으로써 그 조건을 변경할 수 있다. 본 실험에서는 $H / T$ 를 $1.2,1.5,2.0$ 의 3가지로 변경하여 실험을 수 행하였으며, 구조물이 완전히 내려간 심수영역 $(H / T=20.5)$ 에서 의 실험도 부가적으로 수행하였다.

$H / T=\frac{\text { Depth }}{\text { Draft }}$

Table 3 Principal dimensions of KCS model ship

\begin{tabular}{c|c}
\hline Item & Value \\
\hline Scale ratio & 31.6 \\
\hline LPP & $7.278 \mathrm{~m}$ \\
\hline Breath & $1.019 \mathrm{~m}$ \\
\hline Draft & $0.342 \mathrm{~m}$ \\
\hline Displacement & $1.649 \mathrm{~m}^{3}$ \\
\hline
\end{tabular}

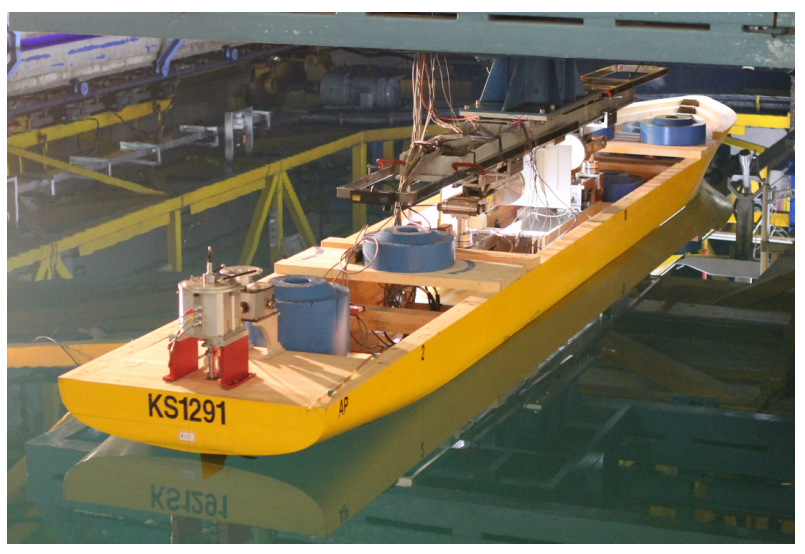

Fig. 5 KCS model ship
실험에 사용된 모형선은 선형이 공개된 KCS선형이며, 천수영 역의 크기를 고려하여 길이가 약 $7.3 \mathrm{~m}$ 인 모형을 사용하였다. 그 제원과 모습은 각각 Table 3, Fig. 5와 같다.

$\mathrm{KCS}$ 모형선은 Fig. 6과 같이 구속모형시험장비에 설치되었고, 모형선의 Surge, Heave, Pitch 운동은 자유롭게 구현되며 Sway, Roll, Yaw 운동은 구속되어 있다. 또한 모형선의 수직방향 무게 중심이 제원과 동일하도록 무게추가 배치되어 있다.

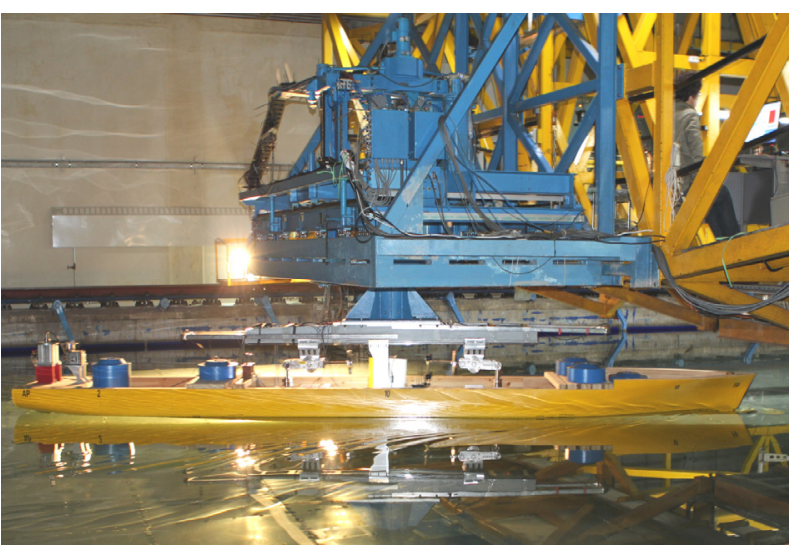

Fig. 6 Captive condition of HPMM device

\section{2 실험 조건}

$\mathrm{KCS}$ 모형선의 천수영역에서의 선박자세 측정은 수평면 구속 모형시험 중 이루어졌으며, 그 중 정적시험 조건은 Table 4와 같 다. 표에서와 같이 선박자세에 변화를 주기 위한 주요변수는 천 수조건 및 모형선의 속도, 프로펠러 RPS, 타각, 사항각 등이다.

Table 4 Static test conditions

\begin{tabular}{|c|c|c|c|c|}
\hline Test type & $\begin{array}{l}\text { Drift } \\
\text { angle }\end{array}$ & $\begin{array}{l}\text { Rudder } \\
\text { angle }\end{array}$ & $\begin{array}{l}\text { Model } \\
\text { speed }\end{array}$ & RPS \\
\hline $\begin{array}{l}\text { Static } \\
\text { rudder }\end{array}$ & $0^{\circ}$ & $\begin{array}{r}0^{\circ} \\
\pm 10^{\circ} \\
\pm 20^{\circ} \\
\pm 30^{\circ} \\
\pm 35^{\circ}\end{array}$ & $\begin{array}{l}0.8007 \mathrm{~m} / \mathrm{s} \text {, } \\
0.6405 \mathrm{~m} / \mathrm{s}, \\
0.5338 \mathrm{~m} / \mathrm{s}\end{array}$ & \multirow{2}{*}{$\begin{array}{c} \\
3.8 \\
(H / T=1.2) \\
3.7 \\
(H / T=1.5)\end{array}$} \\
\hline $\begin{array}{l}\text { Drift \& } \\
\text { rudder }\end{array}$ & 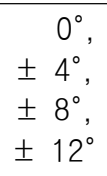 & $\begin{array}{c}3 \text { rudder } \\
\text { angle }\end{array}$ & $0.5338 \mathrm{~m} / \mathrm{s}$ & \\
\hline $\begin{array}{l}\text { Static } \\
\text { drift }\end{array}$ & 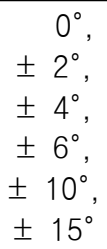 & $0^{\circ}$ & $0.8007 \mathrm{~m} / \mathrm{s}$ & $\begin{array}{c}3.7 \\
(H / T=2.0)\end{array}$ \\
\hline
\end{tabular}

모형선의 속도는 실선 기준 8.75 노트의 속도인 $0.8007 \mathrm{~m} / \mathrm{s}$ (프루드수 0.095)을 기준으로 실험을 수행하였으며, 모형선의 자 항조건은 각 천수조건별로 실험에 의해 결정되었다. 


\section{4. 실험 결과}

Fig. 7 과 같은 천수조건 $(\mathrm{H} / \mathrm{T}=1.2,1.5,2.0)$ 및 심수조건 $(H / T>5.0)$ 에서 모형선의 속도, 프로펠러 RPS, 타각, 사항각 등 의 변화에 따른 선박의 자세변화를 분석하였다. 침하량은 하방이 양의 방향이며, 트림은 선수트림이 음의 방향이다.

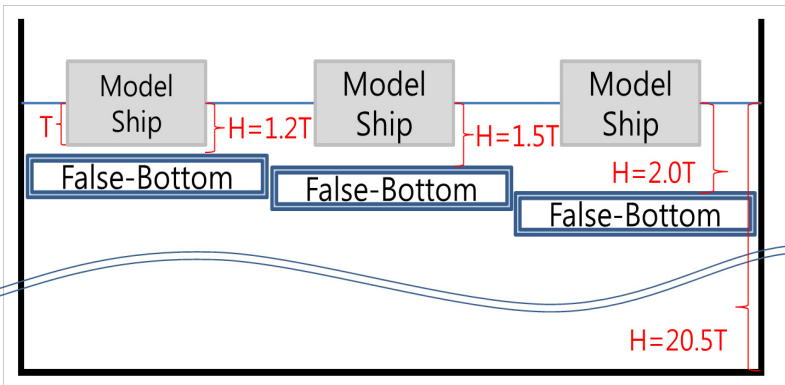

Fig. $7 \mathrm{H} / \mathrm{T}$ condition

\section{1 천수조건, 속도, RPS에 따른 선박의 자세변화}

Fig. 8은 심수영역에서 계측된 KCS 모형선의 운항 중 자세이 다. 모형선의 속도는 $0.8007 \mathrm{~m} / \mathrm{s}$ 이고, 프로펠러 RPS는 3.7 이다. 그래프에서 보듯이 30 초간의 평균 침하량은 $0.001 \mathrm{~m}(0.003 T)$, 평균 트림각은 $-0.06^{\circ}$ 로 속도가 없는 초기 흘수상태에서의 선박 자세에서 크게 변하지 않는 것을 볼 수 있다.

같은 속도에서 천수조건으로 변화시켜 측정한 선박의 평균 자 세는 Fig. 9, Table 5 와 같다. 그래프에서와 같이 $\mathrm{H} / \mathrm{T}$ 가 작아질 수록 모형선의 자세변화는 커지는 것을 확인할 수 있다. 값의 크 기는 작으나 그 변화량을 비교할 때, 천수조건 $\mathrm{H} / \mathrm{T}=1.2$ 일 때의 모형선의 자세변화량은 심수조건일 때의 자세변화량 보다 7 배 이 상 커진 것을 표에서 확인할 수 있다.

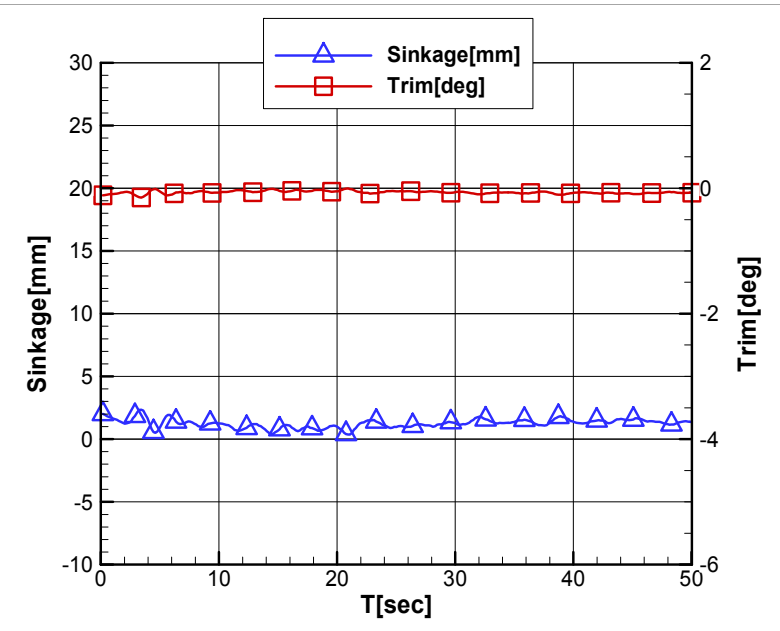

Fig. 8 Time - sinkage, trim $(H / T>5.0)$

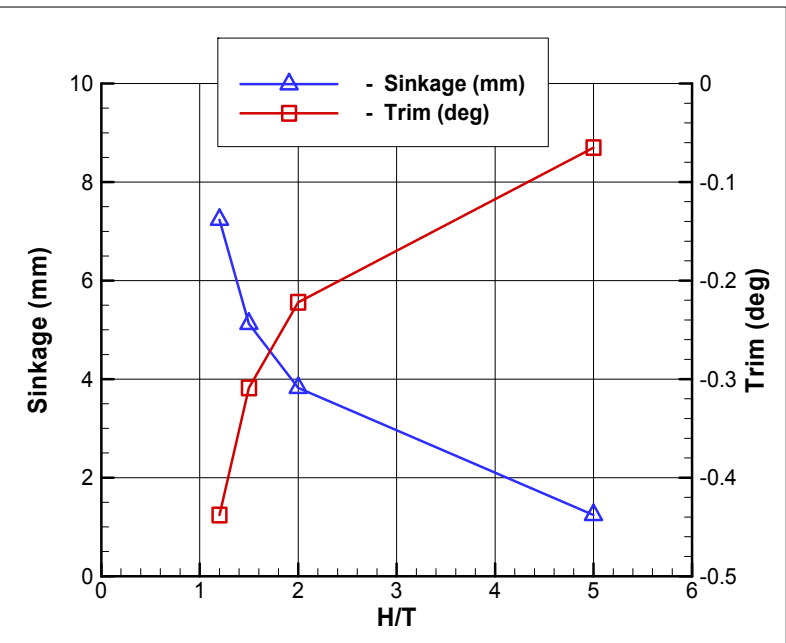

Fig. $9 \mathrm{H} / \mathrm{T}-$ sinkage, trim $(\mathrm{v}=0.8007 \mathrm{~m} / \mathrm{s})$

Table $5 \mathrm{H} / \mathrm{T}$ - sinkage, trim $(\mathrm{v}=0.8007 \mathrm{~m} / \mathrm{s})$

\begin{tabular}{c|c|c|c|c}
\hline Item & $H / T=1.2$ & $H / T=1.5$ & $H / T=2.0$ & $H / T>5.0$ \\
\hline RPS & 3.8 & 3.7 & 3.7 & 3.7 \\
\hline Sinkage (m) & $\begin{array}{c}0.007 \\
(0.020 T)\end{array}$ & $\begin{array}{c}0.005 \\
(0.015 T)\end{array}$ & $\begin{array}{c}0.004 \\
(0.012 T)\end{array}$ & $\begin{array}{c}0.001 \\
(0.003 T)\end{array}$ \\
\hline Trim $\left(^{\circ}\right)$ & -0.44 & -0.31 & -0.22 & -0.06 \\
\hline
\end{tabular}

Fig. 10은 Table 5와 동일한 조건에서 모형선의 속도만을 $0.6405 \mathrm{~m} / \mathrm{s}$ (실선기준 7 노트), $0.5338 \mathrm{~m} / \mathrm{s}$ (실선기준 5.83 노트) 로 변화시켜 계측한 선박의 자세변화 결과이다. 그래프에서 보듯 이 모든 천수조건에서 모형선의 속도가 작아질수록 자세변화는 작아지는 것을 확인할 수 있다. 또한 천수조건 $\mathrm{H} / \mathrm{T}$ 가 작을수록 속도변화에 따른 선박의 침하량 기울기가 커지는 경향을 확인할 수 있다. 즉 천수영역으로 갈수록 속도에 따른 선박의 자세변화 량이 크다고 할 수 있다.

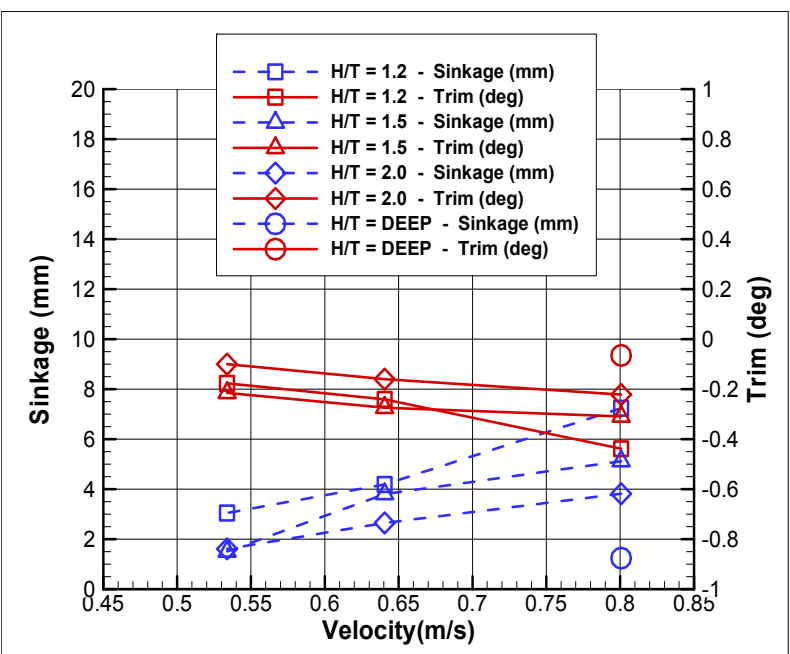

Fig. 10 Velocity - sinkage, $\operatorname{trim}(H / T=1.2,1.5$, 2.0) 
다만 $0.6405 \mathrm{~m} / \mathrm{s}$ 와 $0.5338 \mathrm{~m} / \mathrm{s}$ 의 속도에서의 트림각 크기는, $H / T=1.2$ 조건의 결과가 $H / T=1.5$ 조건의 결과보다 더 작은 것 을 볼 수 있는데, 이는 천수바닥면의 불균일, 모형선의 흔들림 등 에 의한 실험상의 오차로 보이며, 해당조건에 대한 반복 실험과 선박의 속도, 종동요 주기, $\mathrm{H} / \mathrm{T}$ 변화에 따른 선체압력 분포의 동 적 변화에 대한 CFD 해석 등의 추가적인 연구가 필요하다.

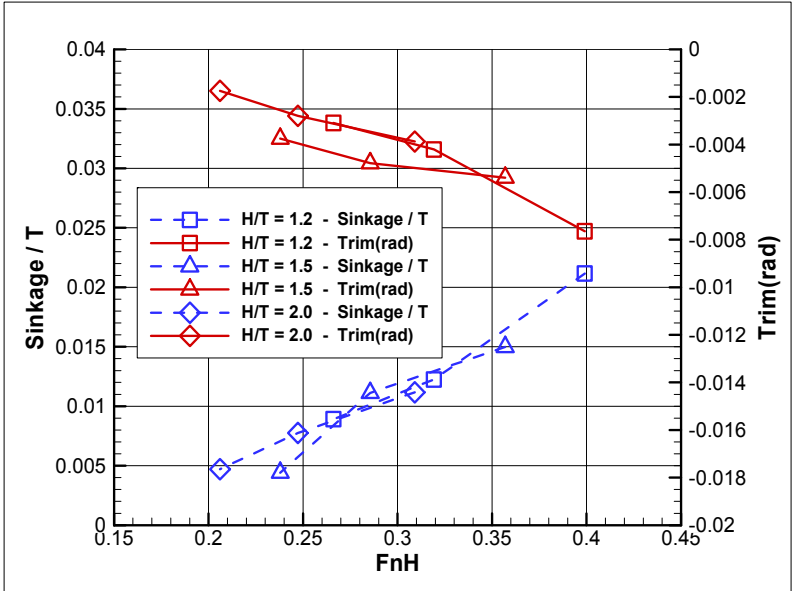

Fig. $11 F_{n H}-$ sinkage, $\operatorname{trim}(\mathrm{H} / \mathrm{T}=1.2,1.5,2.0)$

Fig. 11은 Fig. 10의 결과를 식(2)와 같은 수심프루드수를 기 준으로 나타낸 그래프이다. 그래프에서 보듯이 $F_{n H}$ 가 커질수록, 즉 모형선의 속도 $\mathrm{V}$ 가 증가하거나 수심 $\mathrm{H}$ 가 작아질수록 모형선 의 자세변화가 커지는 것을 다시 확인할 수 있다.

$F_{n H}=\frac{V}{\sqrt{g H}}$

여기서 $\vee$ 는 모형선의 속도, $g$ 는 중력가속도, $H$ 는 수심이다.

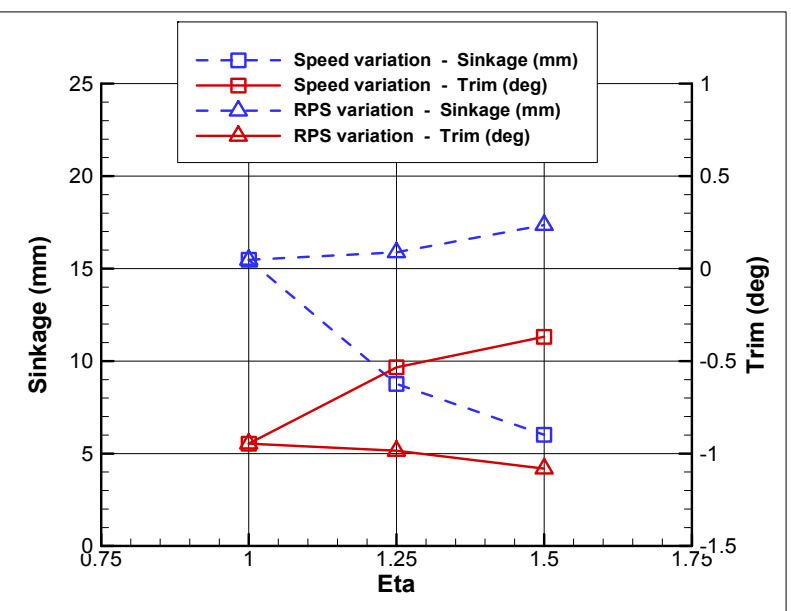

Fig. $12 \eta$ - sinkage, trim $(H / T=1.2)$ (Park, et al., 2013)

Fig. 12는 천수조건 $H / T=1.2$ 일 때 선박의 속도와 프로펠러
$\mathrm{RPS}$ 를 각각 변화시켜, 식(3)의 동일한 $れ$ 조건(선박추진비)에서의 선박의 자세변화를 계측한 결과이다.

$\eta=\frac{J_{c}}{J}=\frac{\frac{V_{c}}{n_{c} D}}{\frac{V}{n D}}=\frac{n V_{c}}{n_{c} V}$

여기서 하첨자 $V_{c}, n_{c}$ 는 기준이 되는 속도 $(0.8007 \mathrm{~m} / \mathrm{s})$ 및 $\mathrm{RPS}$ (3.8)를 의미하며, $V, n$ 은 $れ$ 조건을 변경하기 위한 실험 조 건에서의 모형선 속도, 프로펠러 RPSO이다.

그래프에서 보듯이 RPS의 증가는 모형선의 침하량과 트림량 크기를 조금씩 증가시키고, 모형선 속도의 감소는 그것을 감소시 키는 것을 볼 수 있다. 또한 같은 $n$ 조건에서 모형선의 자세변화 는 프로펠러의 RPS증가량보다 모형선의 속도감소량에 의해 더 영향을 받은 것을 확인할 수 있다. 이러한 현상은 선박의 자세변 화에 미치는 선박의 선저와 바닥면 사이의 유동 흐름이 선미의 좁은 범위에 영향을 미치는 프로펠러의 RPS변화보다 선저면 전 범위에 걸친 선박의 속도 변화에 상대적으로 더 큰 영향을 받고 있기 때문인 것으로 판단된다.

\section{2 천수조건, 타각에 따른 선박의 자세변화}

Fig. 13은 주어진 기준속도에서 천수조건별 타각의 변화에 따 른 모형선의 자세를 계측한 결과이다. 타각을 $-30^{\circ}$ 에서 $30^{\circ}$ 까지 $10^{\circ}$ 간격으로 변화시키며 모형선의 자세를 계측한 결과, 그래프 에서와 같이 타각의 변화에도 모형선의 자세변화가 크지 않은 것 을 볼 수 있다.

즉 천수영역에서 타각의 변화는 선박의 자세에 큰 영향을 미치 지 않는 것으로 볼 수 있다. 이러한 결과 역시 선미에 위치한 방 향타의 타각변화로 발생되는 유체의 변화된 흐름은 선미에 국부 적으로만 발생하고, 이는 앞에 있는 선체에는 큰 영향을 미치지 못하고 선미방향으로 빠져나가기 때문인 것으로 판단된다.

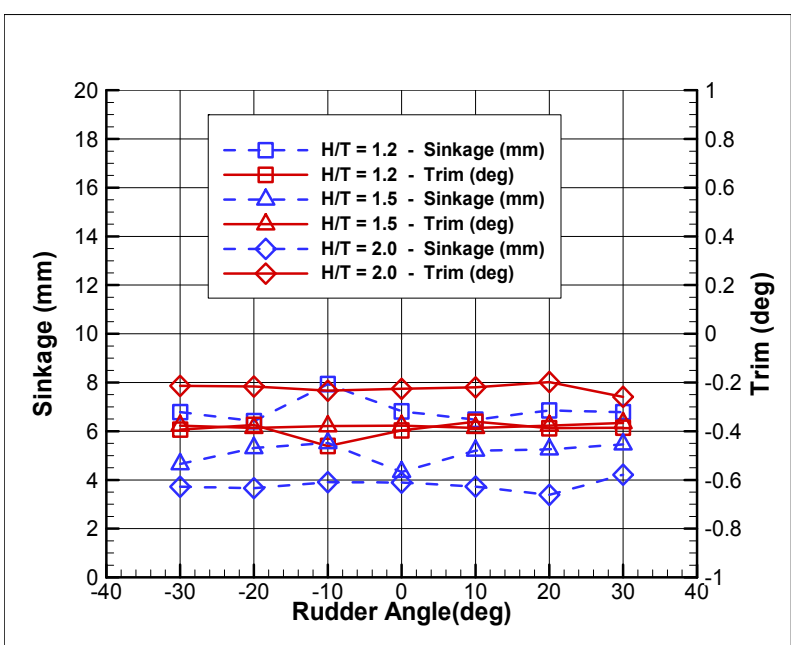

Fig. 13 Rudder test on false-bottom ( $v=0.8007 \mathrm{~m} / \mathrm{s}$ ) 


\section{3 천수조건, 사항각에 따른 선박의 자세변화}

Fig. 14는 주어진 기준속도에서 천수조건별 사항각의 변화에 따른 모형선의 자세를 계측한 결과이다. 사항각을 $-15^{\circ}$ 에서 $15^{\circ}$ 까지 약 $5^{\circ}$ 간격으로 변화시키며 모형선의 자세를 계측한 결과, 그래프에서 보듯이 사항각의 변화는 선박의 자세와 밀접한 관련 이 있음을 볼 수 있다. 즉 사항각이 커질수록 모형선의 자세변화 는 커지는 것을 확인할 수 있는데, 사항각이 0도일때의 평균 침 하량 및 평균 트림각은 사항각이 15도로 변하면서 약 2배 증가한 것을 볼 수 있다. 또한 천수조건 $\mathrm{H} / \mathrm{T}$ 가 작을수록 사항각변화에 따른 선박의 자세변화량 기울기가 커지는 경향을 확인할 수 있다. 즉 천수영역으로 갈수록 사항각에 따른 선박의 자세변화량이 크 다고 할 수 있다.

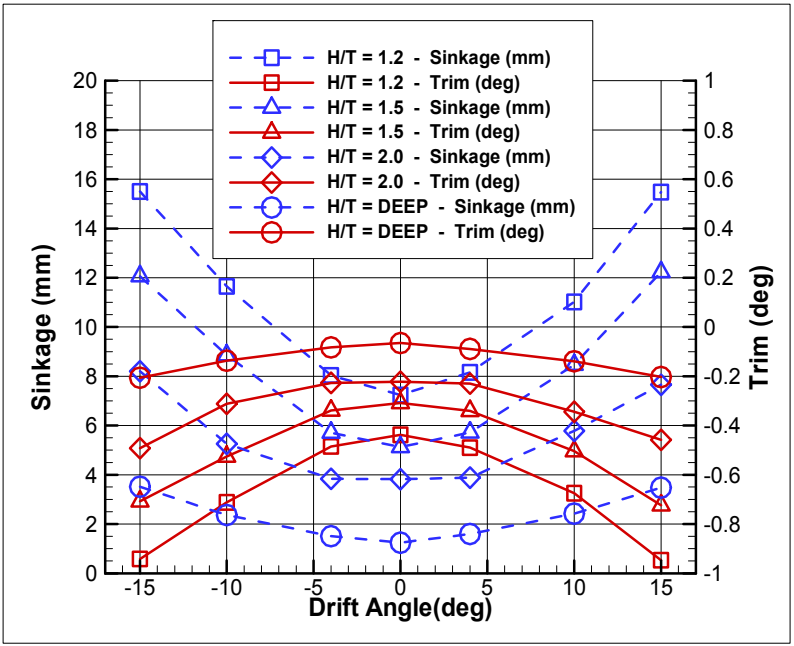

Fig. 14 Static drift test on false-bottom ( $v=0.8007 \mathrm{~m} / \mathrm{s})$

이러한 현상 역시 선저와 바닥면의 유동변화에 기인한 것으로 추정할 수 있다. 즉 사항각이 커짐에 따라 선체의 중심선이 아닌 측면부에서 유체의 유입이 시작되고, 그에 따라 선체의 선저를 지나 반대측면으로 유체가 흐를 때에는 선저의 급격한 형상변화 에 따라 유체흐름 역시 급격히 변화했을 것으로 추정할 수 있다.

\section{4 결과 비교}

$\mathrm{KCS}$ 선형의 천수영역에서의 선박자세 측정 결과를 비교하기 위하여 식(4)-(6)와 같은 추정식을 이용하여 선박의 침하량을 계 산하였다.

Tuck/Huuska 추정식 (Hewlett, et al., 2002)

$\frac{S_{L C F}}{L p p}=C_{s} C_{\nabla} \frac{F_{n H}^{2}}{\sqrt{1-F_{n H}^{2}}}$

여기서 $S_{L C F}$ 는 부면심에서의 침하량, $C_{s}$ 는 침하량 계수(1.3
- 1.5) (Tim, 2010), $C_{\nabla}$ 는 $\frac{\nabla}{L p p^{3}}$ 로 정의되는 부피계수, $F_{n H}$ 는 수심프루드수를 의미한다.

Barrass 2 추정식 (Hewlett, et al., 2002)

$S_{\text {m ax }}=\frac{1}{30} C_{B}\left[\frac{A_{s}}{A_{c}-A_{s}}\right]^{\frac{2}{3}} V^{2.08}$

여기서 $S_{\mathrm{max}}$ 는 선박의 침하량, $C_{B}$ 는 방형 계수, $A_{c}$ 는 수 로의 단면적, $A_{s}$ 는 선박의 수선면 아래 단면적, $\mathrm{V}$ 는 선박의 속 도를 의미한다.

Eryuzlu et al. 추정식 (Hewlett, et al., 2002)

$S_{\text {max }}=0.298\left(\frac{H^{2}}{T}\right) F_{n H}^{2.289}\left(\frac{H}{T}\right)^{-2.972} K_{b}$

여기서 $S_{\mathrm{max}}$ 는 선박의 침하량, B는 선박의 폭, T는 선박의 흘수, $\mathrm{H}$ 는 수심, $F_{n H}$ 는 수심프루드수를 의미하며, $K_{b}$ 는 수로 의 폭이 9.61B이상일 경우 1로 한다.

또한 Fig. 15, Fig. 16처럼 Jachowski (2008)와 Shin \& Choi (2001)의 CFD 해석 연구결과를 비교자료로 활용하였으며, 기술 된 CFD 해석 조건은 Table 6과 다음과 같다.

Table 6 CFD analysis conditions

\begin{tabular}{c|c|c|c|c}
\hline Item & Scale & $\begin{array}{c}\text { Rudder \& } \\
\text { Propeller }\end{array}$ & $\begin{array}{c}\text { Boundary } \\
\text { condition }\end{array}$ & $\begin{array}{c}\text { Number of } \\
\text { grid points }\end{array}$ \\
\hline Experiment & $1: 31.6$ & 0 & - & - \\
\hline Jachowski & $1: 31.6$ & $X$ & velocity inlet & $0.54-0.73 \mathrm{M}$ \\
\hline Shin \& Choi & $1: 31.6$ & $\mathrm{X}$ & pressure inlet & $0.7 \mathrm{M}$ \\
\hline
\end{tabular}

Jachowski 결과 (Jachowski, 2008)

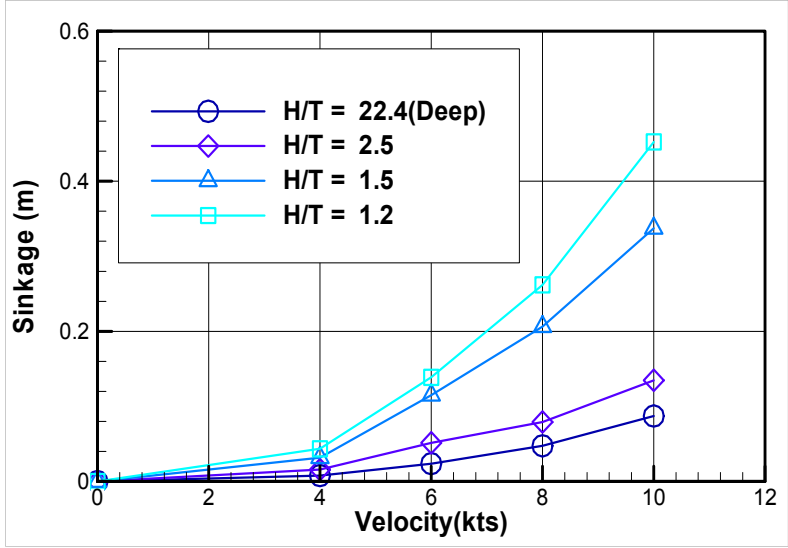

Fig. 15 Prediction result for ship sinkage by Jachowski's method(full scale) 
Shin \& Choi 결과 (Shin \& Choi, 2011)

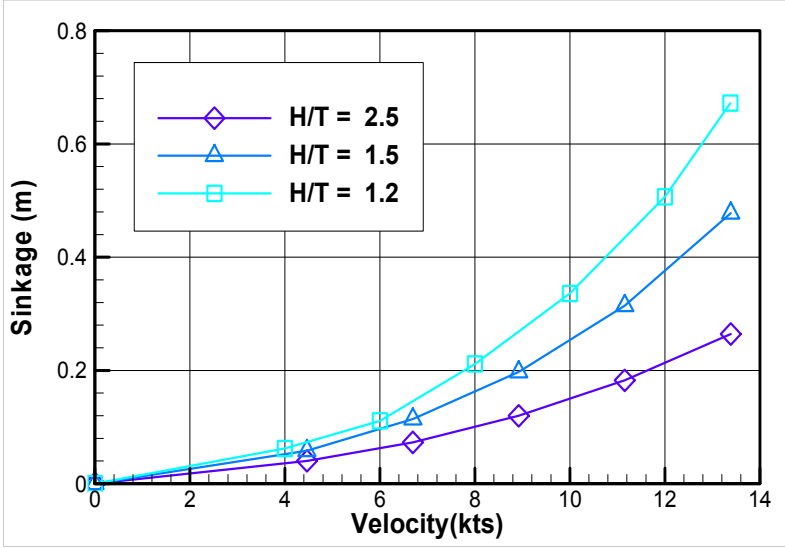

Fig. 16 Prediction result for ship sinkage by Shin \& Choi's method(full scale)

3가지 추정식과 $\mathrm{CFD}$ 해석에 의한 $\mathrm{KCS}$ 선형의 선박침하 추정량 과 실험에 의한 $\mathrm{KCS}$ 모형선의 선박침하 계측값을 실선크기로 같 이 나타내면 Fig. 17-19와 같다. Tuck/Huuska 추정식의 $C_{s}$ 는 1.5로 하였고, Barrass 2 추정식 및 Eryuzlu et al. 추정식의 수로 폭은 선박폭의 10 배로 하였다.

그래프에서 보듯이 실험에서 얻은 선박의 침하량은 추정식에 서 얻은 침하추정량 및 $\mathrm{CFD}$ 해석결과로부터 얻은 침하추정량과 비교할 때, 속도에 따라 그 양이 증가하는 동일한 경향성을 살펴 볼 수 있다. 추정식의 경우 특정계수의 설정값에 따라 그 추정량 이 변할 수 있으므로, 속도에 따른 선박침하량의 경향성 및 그 크 기의 정도를 확인할 수 있다는 점에서 의의가 있을 것으로 보인 다. 선행 $\mathrm{CFD}$ 해석 연구결과는 실제 실험결과와 약간의 차이를 보이고 있음을 확인할 수 있다. CFD해석의 경우 실험조건과 달 리 선체만으로 해석을 수행하였고, 침하량 역시 선저면의 압력변 화량을 통해 부력감소량을 먼저 계산하고, 부력감소량으로 침하 량을 계산하였기에 실험결과와 차이가 있는 것으로 보인다.

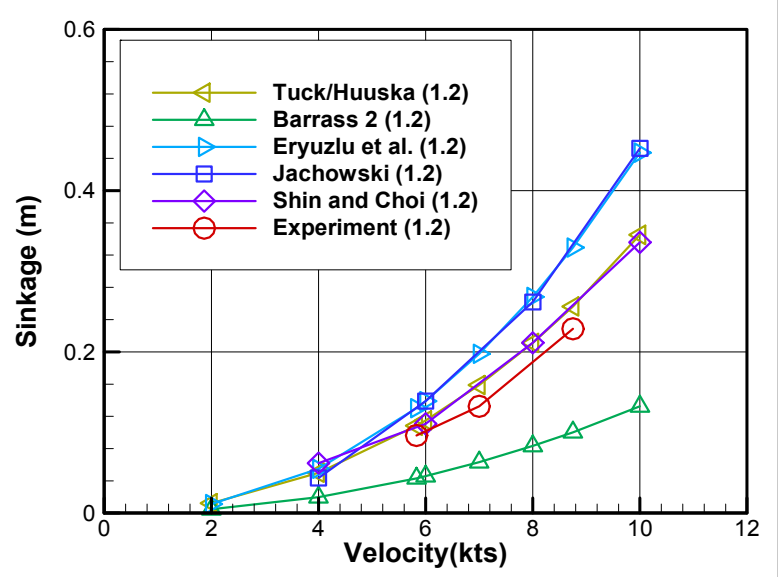

Fig. 17 Comparison of ship sinkage results by empirical formulas, CFD methods and experiment $(H / T=$ 1.2, full scale)

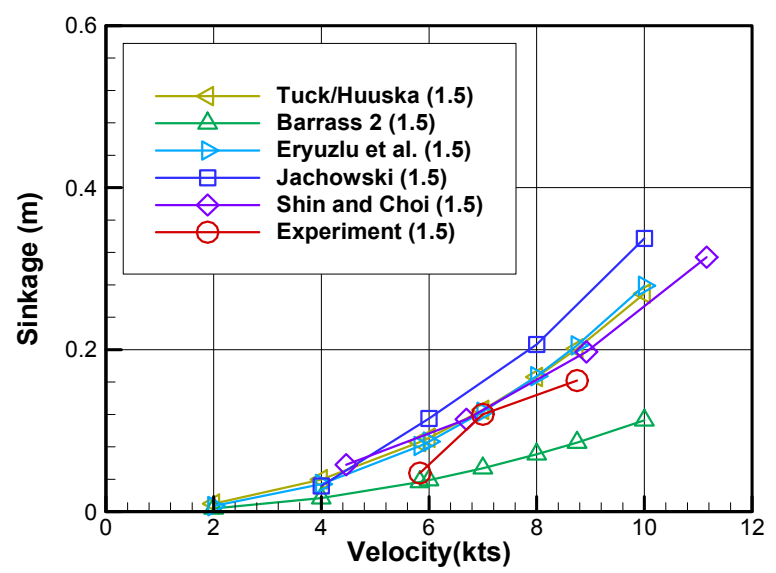

Fig. 18 Comparison of ship sinkage results by empirical formulas, CFD methods and experiment $(\mathrm{H} / \mathrm{T}=$ 1.5 , full scale)

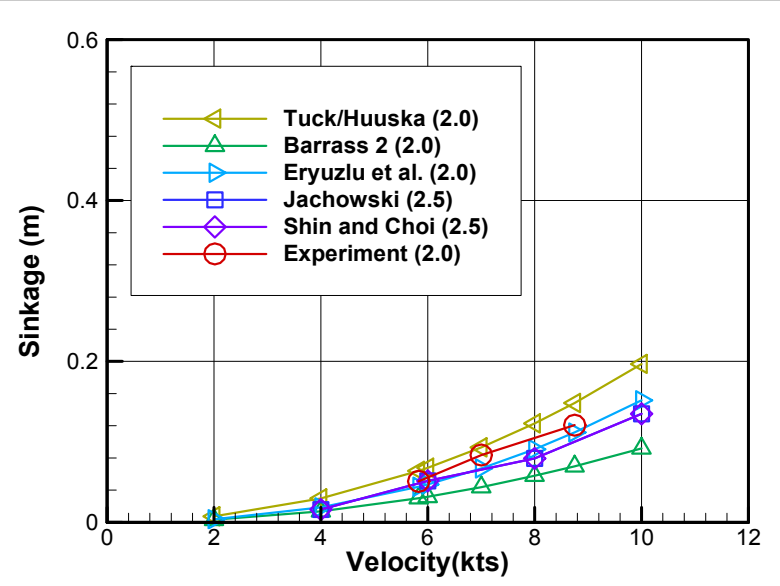

Fig. 19 Comparison of ship sinkage results by empirical formulas, CFD methods and experiment $(H / T=$ 2.0, full scale)

\section{5. 결 론}

본 논문에서는 영상기반 선박자세 측정시스템을 활용하여, 저 속으로 운항하는 $\mathrm{KCS}$ 모형선에 대하여 천수영역에서의 자세변화 를 실험을 통하여 분석하였다. 3 가지 천수조건 $(\mathrm{H} / \mathrm{T}=1.2,1.5$, 2.0)을 구성하였고, 모형선의 속도, 타각, 사항각에 따른 모형선 자세변화를 확인하였다.

그 결과로,

- 선박의 속도가 커질수록, 천수조건 $\mathrm{H} / \mathrm{T}$ 가 작을수록 선박의 자세변화가 커지는 선박의 스쿼트 현상을 실험을 통해 확인 하였다.

- 프로펠러 RPS 증가는 선박의 자세변화를 커지게 하는 것으 로 확인되나, 타각 변화는 선박의 자세에 큰 영향을 미치지 않는 것으로 보인다. 
- 선박의 사항각이 커질수록 선박의 자세변화는 커지며, 천수 조건 $\mathrm{H} / \mathrm{T}$ 가 작을수록 그 영향이 더 크다.

또한 계측된 모형선의 침하량을 추정식 및 상용 전산유체역학 해석프로그램을 이용한 선행 연구결과와 비교하였다.

그 결과로,

- 추정식결과 비교를 통해 계측된 선박의 침하량이 추정식의 경향성에 따르고 있음을 확인하였고, 그 크기에 있어서 추 정식이 제안하는 범위 안에 있음을 확인할 수 있었다.

- 선행 CFD 연구결과 비교를 통해 계측된 선박침하량은 추정 량과 약간의 차이가 있음을 확인하였고, 이는 실험조건의 차이로 추정된다.

향후 연구사항으로는 선박의 스쿼트 현상에 미치는 유동의 흐 름 특성을 확인하기 위하여 실험 조건과 동일한 환경에서 $\mathrm{KCS}$ 선 형의 CFD해석을 수행할 예정에 있다. 이를 통하여 프로펠러 $\mathrm{RPS}$, 타각, 사항각 변화 등에 의한 유동 흐름의 변화와 선박의 자세변화 관계를 규명하고, 실험결과와 비교할 예정이다.

또한 동일 천수영역시설을 이용하여 KVLC2(kriso very large crudeoil carrier)선형, KLNG(kriso liquified natural gas carrier)선 형에 대하여 동일한 실험을 수행하여, 선형의 차이에 따른 선박 의 자세변화 차이를 비교 분석할 예정이다.

\section{후 기}

본 연구는 한국해양과학기술원/선박해양플랜트연구소의 주요 연구사업 "제한수역에서의 선박운항 시뮬레이션 기술 고도화 (2/3)[PES156F]"의 연구 결과 중 일부임을 밝힌다.

\section{References}

Beaulieu, C. Gharbi, S. Ouarda, T.B.M.J. Charron, C. \& Aissia M.A.B, O., 2012. Improved Model of Deep-Draft Ship Squat in Shallow Waterways Using Stepwise Regression Trees. Journal of Waterway, Port, Costal, and Ocean Engineering, 138(2), pp. 80-90.

Beaulieu, C. Gharbi, S. Ouarda, T.B.M.J. \& Seidou, O., 2009. Statistical Approach to Model the Deep Draft Ships' Squat in the St.Lawrence Waterway. Journal of Waterway, Port, Costal, and Ocean Engineering, 135(3), pp.80-90.
Hewlett, C. Daggett, L. Stocks, D. \& Vladimir, A., 2002. Dynamic Squat and Under-Keel Clearance of Ships in Confined Channels. 30th International Navigation Congress, S10B, pp.152-163.

Jachowski J., 2008. Assessment of Ship Squat in Shallow Water using CFD. Archives of Civil and Mechanical Engineering, VIII(1), pp.27-36.

Kim, H.E. Seo, S.H. \& Lee, Y.G., 2000. An Experimental Study of the Shallow Water Effect on Series60 Hull Form. Journal of the Society of Naval Architects of Korea, 37(3), pp.21-26.

Kwon, S.Y. \& Lee, Y.G., 2004. A Study on the Resistance Characteristics of High-Speed Ship in Shallow Water Condition. Journal of the Society of Naval Architects of Korea, 41(2), pp.1-11.

Park, B. Yun, K. \& Yeo, D.J., 2013. On the preparation of maneuvring captive model test on the false-bottom. 13th Asia Conference on Maritime System and Safety Research, Daejeon, Republic of Korea, 8-9 August 2013.

Shin, H.K. \& Choi, S.H., 2011. Analysis of Ship Squat in Confined Water Using CFD. Journal of the Society of Naval Architects of Korea, 48(4), pp.317-324.

Taylan, M., 2001. Behavior of Ships in Shallow and Restricted Waters. Mathematical \& Computational Applications, 6(1), pp.1-11

Tim, G. \& Kim, K., 2007. Full-Scale Measurements of Containership Sinkage, Trim and Roll. Australian Naval Architect, 11(2), pp.30-36.

Tim, P., 2010. A Brief History of Mathematical Ship-Squat Prediction, Focussing on the Contributions of E.O. Tuck. Journal of Engineering Mathematics, 70, pp.5-16.

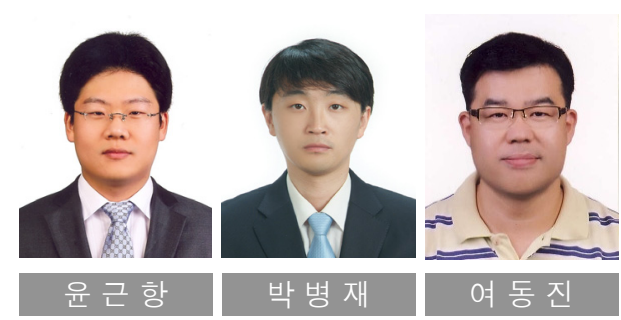

